
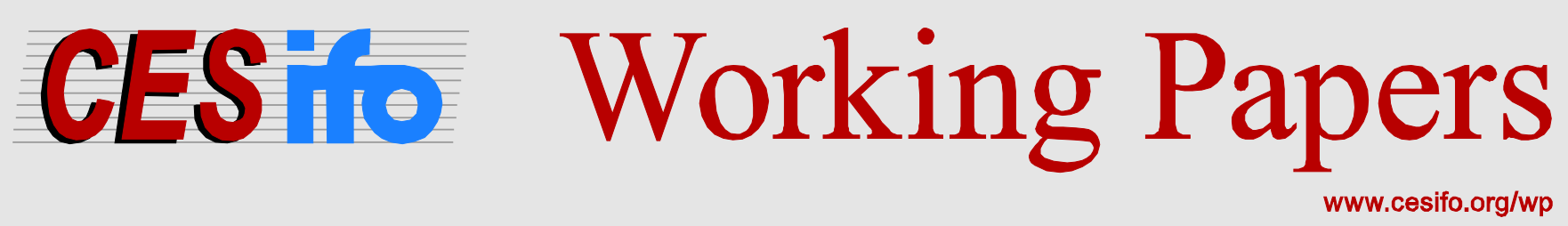

\title{
Corporate Philanthropy and Productivity: Evidence from an Online Real Effort Experiment
}

\author{
Mirco Tonin \\ Michael Vlassopoulos
}

CESIFO WORKING PAPER NO. 4778

CATEGORY 13: BEHAVIOURAL ECONOMICS

APRIL 2014

An electronic version of the paper may be downloaded

- from the SSRN website:

- from the RePEc website:

- from the CESifo website:

wWw.SSRN.com

www.RePEc.org

www.CESifo-group.org/wp

\section{CESifo}




\title{
Corporate Philanthropy and Productivity: Evidence from an Online Real Effort Experiment
}

\begin{abstract}
Contributing to a social cause can be an important driver for workers in the public and nonprofit sector as well as in firms that engage in Corporate Philanthropy or other Corporate Social Responsibility policies. This paper compares the effectiveness of social incentives that take the form of a donation received by a charity of the subject's choice - to financial incentives. We find that social incentives lead to a $13 \%$ rise in productivity, regardless of their form (lump sum or related to performance) or strength. The response is strong for subjects with low initial productivity (30\%), while high-productivity subjects do not respond. When subjects can choose the mix of incentives half sacrifice some of their private compensation to increase social compensation, with women more likely than men. Furthermore, offering subjects some discretion in choosing their own payment scheme leads to a substantial improvement in performance. Comparing social incentives to an equally costly increase in private compensation for low productivity subjects reveals that the former are less effective in increasing productivity, but the difference is small and not statistically significant.
\end{abstract}

JEL-Code: D640, J240, J320, L300, M140, M520.

Keywords: financial incentives, social incentives, prosocial behavior; real effort experiment, corporate philanthropy, corporate social responsibility, gender.

\author{
Mirco Tonin \\ Department of Economics \\ School of Social Sciences \\ University of Southampton \\ UK - Southampton SO17 1BJ \\ m.tonin@soton.ac.uk
}

\author{
Michael Vlassopoulos \\ Department of Economics \\ School of Social Sciences \\ University of Southampton \\ UK - Southampton SO17 1BJ \\ m.vlassopoulos@soton.ac.uk
}

\section{April 2014}

We thank the editor, Uri Gneezy, an associate editor, three anonymous referees, Jim Andreoni, Chiara Binelli, Stefano DellaVigna, Robert Dur, Leonie Gerhards, Sera Linardi, Miltos Makris, Bruce Shearer, Adam Szeidl and the audiences at University of Vienna, University of Bristol, Cardi_Business School, University of Reading, University of Verona, the Institute of Education, CEU, University of Regensburg, IZA, Fondazione ENI Enrico Mattei, Bicocca University, University of Aachen, University of Brescia, ALBA, the 2012 Thurgau Experimental Economics Meeting, the 2012 CEPR Public Policy Symposium, the 2012 Young Economists' Workshop on Social Economy, the 2011 ESA International Meeting, the ZEW Workshop on Behavioural Personnel Economics, and the Workshop on the Social Dimension of Organizations for helpful comments. We thank Jiadi Yao and Juan Correa for excellent research assistance. This work was supported by the Economic and Social Research Council [grant number RES-061-25-0461]. This paper supersedes an earlier working paper circulated under the title "Social Incentives Matter: Evidence from an Online Real Effort Experiment”. 


\section{Introduction}

How to motivate workers is a question of great interest for academics and practitioners alike. In economics, for the most part, attention has been devoted to the role of financial incentives (piecerates, bonuses, stock options, etc.). The effectiveness of financial incentives in raising productivity has found empirical support in sectors such as manufacturing and agriculture (e.g. Lazear, 2000; Shearer, 2004; Bandiera et al., 2005). Lately, economists have started analyzing theoretically optimal incentives when workers may also have prosocial concerns, namely, they are motivated by making a contribution to a social cause (e.g. Besley and Ghatak, 2005; Delfgaauw and Dur, 2007, 2008; Francois, 2000, 2007; Prendergast, 2007). The link between a worker's job and a social cause can arise naturally in the public sector and certain care-related sectors (e.g. health, education, social services etc.) or can be induced in any job through the implementation of Corporate Philanthropy (which in 2011 reached $\$ 14.5$ billion in the US; Giving USA, 2012) or other related Corporate Social Responsibility (CSR) policies. ${ }^{1}$ Despite the theoretical interest in this type of worker prosocial motivation, there is not much empirical evidence on the effectiveness and relative importance of incentives that appeal to such concern compared to traditional financial incentives. ${ }^{2}$

This paper reports results from a real effort experiment in which subjects perform remotely an online data entry task, facing different combinations of financial and social incentives. Financial incentives are represented by a standard piece rate, while social incentives take the form of a donation received by a charity of the subject's choice - either lump sum or related to the subject's performance. ${ }^{3}$ What we find is that social incentives matter as they are effective in motivating subjects, inducing a $13 \%$ rise in productivity. The response is greater $(30 \%)$ for subjects with low initial productivity, while subjects who performed strongly at the very beginning do not respond to either social or financial incentives. Interestingly, subjects react equally whether the donation to the charity is lump-sum or related to performance; in the latter case, tripling the donation piece-rate does not increase productivity any further. ${ }^{4}$ One interpretation for this finding is that

\footnotetext{
${ }^{1}$ See Benabou and Tirole (2010) and Kitzmueller and Shimshack (2012) for an overview of the economic perspective on CSR. More specific to our labor market focus, Brekke and Nyborg (2008) argue theoretically that CSR can be used by employers as a labor market screening device.

${ }^{2}$ There is a substantial business literature that uses surveys to examine the impact of CSR on potential or existing employees. The usual finding is that companies with a high level of CSR are more attractive for job seekers and that CSR is positively associated with employees' commitment to the firm. For recent contributions, with references to previous studies, see Evans and Davis (2011), and Stites and Michael (2011). For a recent contribution to the empirical literature on public sector motivation, see Gregg et al. (2011). For a perspective of prosocial motivation in the workplace through the lens of organizational behavior, see Grant and Berg (2011).

${ }^{3}$ Gneezy and Rey-Biel (2014) compare the effectiveness of contingent and non-contingent incentives in generating responses to a marketing survey and find that contingent incentives are more cost-effective.

${ }^{4}$ This finding is consistent with the results in Tonin and Vlassopoulos (2010). It is also in line with experimental evidence regarding the efficiency of matching grants in raising charitable giving. For instance, Karlan and List (2007)
} 
the presence of social incentives enhances the sense of identification with the job (and particularly so for those lacking the intrinsic motivation to perform the job), an aspect that is emphasized as being an important determinant of worker effort in organizations by Akerlof and Kranton (2005). Consistent with this finding of lack of gradient in the response to different levels of social incentives, in reality, firms employ a variety of Corporate Philanthropy practices: some firms link their charitable activities to performance, for instance, by pledging to contribute a given percentage of their profits or revenues, ${ }^{5}$ while other firms opt not to link their Corporate Philanthropy budget to profits - at least not in an explicit way.

To assess whether social incentives are economically significant, we compare their effectiveness in boosting productivity to the one of financial incentives for the subgroup of subjects that were found to be responsive to incentives, namely, low productivity subjects. We find that social incentives are less effective in motivating subjects as compared to financial incentives, but the difference is not large. More specifically, a $5 \mathrm{p}$ piece rate donated to a charity generates a similar increase in productivity as a $5 \mathrm{p}$ increase in the private piece rate. We conclude that the fact that social incentives have a significant effect on productivity may be one of the reasons behind the increasing importance of CSR policies, in particular when this is added to the positive impact on customers and investors documented in other studies (e.g. Gneezy et al., 2010, 2012; Elfenbein and McManus, 2010; Casadesus-Masanell et al., 2009; Servaes and Tamayo, 2013). In addition, our findings indicate that in occupations and sectors with characteristics that engender prosocial behavior, such as, health, education and social care, a given level of productivity can be achieved with less financial incentives, a point that had been made in the theoretical literature (e.g. Besley and Ghatak, 2005) but had seen little direct empirical evidence.

Our experiment involves four one-hour sessions that each subject had to complete within a one-week period. In the first session, all subjects work under a baseline piece rate. From session 2 onwards, we randomly assign subjects into 4 groups. Subjects in Group 1 work under the same piece rate for the remaining three sessions. This allows us to measure any trend in productivity, due to, for instance, learning or boredom. Subjects in Group 2 face different piece rates in sessions 2-4. This allows us to measure the effect of financial incentives on performance. Subjects in the remaining two groups work in sessions 2 and 3 under the same baseline piece rate, plus they face a social incentive, in the form of a donation received by a charity of the subject's choice. In particular, for Group 3 this donation can be either lump-sum or related to performance, while subjects in Group 4

find that matching increases giving but tripling the matching rate does not have additional impact, while Huck and Rasul (2011) even find a decrease in actual donations given as the matching rate increases from 0 to 0.5 and 1.

${ }^{5}$ One such example from the UK is the so-called Percent Club for companies that pledge to donate at least $1 \%$ of their pre-tax profits to charitable causes. 
face two performance-related social incentives of different strength. Through these two treatments, we identify the impact of social incentives on productivity. In the final session, subjects in groups 3 and 4 can choose how to divide a piece rate between themselves and a charity of their choice, thus being able to choose their preferred mix of financial and social incentives. ${ }^{6}$

This last treatment allows us to investigate whether, when given the opportunity, subjects choose a compensation scheme embedding social incentives, sacrificing personal monetary rewards. We find that around half of our subjects choose a compensation with a social element, with women being more likely than men. Notably, we find that offering subjects some discretion in choosing their own payment scheme leads to a substantial improvement in performance, in line with Charness et al. (2012) who find that delegating the wage decision to workers increases effort in a gift exchange experiment.

We also find that subjects who self-report having volunteered in the previous year are more responsive to social incentives than subjects who did not, indicating consistency between prosocial behavior displayed in the experiment and outside. Finally, as we have precise measures of both quantity and quality of output, we can test whether social incentives have a different impact on the two, and we find that both are equally affected.

Methodologically, an experimental approach to assessing the effects of alternative types of incentives on productivity has several known advantages, aptly summarized in Charness and Kuhn (2011). Experiments have been recently used to shed light on a variety of issues as diverse as promotion tournaments (Altmann et al., 2012), the role of incentives for the self-selection of workers (Dohmen and Falk, 2009), and the role of reference points for the provision of effort (Abeler et al., 2011). It is worth highlighting here some unique features of our experimental design. First, the fact that the experiment is conducted online and not in a lab makes the role of subjects' motivation a more important determinant of performance. This is because in a lab subjects usually have limited opportunities to pursue alternative activities and, also, the amount of (perceived) scrutiny may be higher. Second, studying the performance of individuals who work remotely is interesting in its own right given the recent trend of homeworking and teleworking in which an increasing number of jobs, primarily in sales, entails the employee working from home. Third, the short term and one-off nature of the job reduces the confounding effect of incentives driven by concerns for reputation-

\footnotetext{
${ }^{6}$ There are several instances where firms promote similar schemes. In the UK, for instance, many firms give the opportunity to employees to make tax-free donations to their chosen charities, often with matched employee contributions. According to figures by the Payroll Giving Centre, in 2011/12 more than 735,000 employees participated in the scheme, (see www.payrollgivingcentre.com). In the US a survey by the Center on Philanthropy at Indiana University (undated) finds that in 2008-2009 36\% of full-time employees worked at a company offering some type of workplace giving campaign, with $54 \%$ of those asked to give actually donating.
} 
building by the employees. Namely, employees may respond to social incentives not because they care about the incentives in themselves but because they want to signal their prosocial type to the employer, if they think that this will foster their career perspectives and therefore their future earnings, for instance, because prosocial types are expected to be less likely to shirk. In a setting with long-term employment relationships, even if it was possible to engineer an exogenous change in compensation, it would be very difficult to isolate this career concern from the direct motivational impact of social incentives. On the other hand, in an experimental setting like ours there exists a concern that the response to social incentives that we find may be confounded by a desire to conform to what experimenters expect subjects to do. We believe that this type of demand effect is reduced in our experiment because subjects work remotely and never have to meet face to face with an experimenter. Also, when we ask subjects to either share a piece rate with a charity or share parts of their earnings with a charity we find far from complete adherence to behavior that would be considered socially desirable. Beyond this, some amount of scrutiny by peers and superiors is a ubiquitous feature of workplace environments, so the fact that in our experiment subjects' performance is observed, albeit in a very nonintrusive way, is not necessarily a vice.

Other experimental studies that look at the impact of charitable donations on real effort are Ariely et al. (2009), Tonin and Vlassopoulos (2010), Imas (2014) and on induced (chosen) effort Fehrler and Kosfeld (2014) and Koppel and Regner (2013). None of these studies compare financial to social incentives and look at the effect of giving workers the opportunity to choose the preferred compensation scheme, which, in addition to demonstrating the importance of social incentives, are the main contributions of the current paper.

The rest of the paper is organized as follows. The next section describes the experimental design; section 3 provides some descriptive analysis of the sample and the experimental data; section 4 presents the main and auxiliary regression results on the productivity impact of financial and social incentives. The last section offers some concluding remarks.

\section{The Online Experiment}

\subsection{Description}

We set up a computer-based real effort task that subjects could perform remotely on their own computer as long as it had internet access, and required little training and prior experience other than basic computer skills. The task involved entering bibliographic records in an online repository 
platform. In particular, subjects entered various elements (title, author(s) names, year of publication, name of journal, volume, issue and pages) of academic publications, the first page of which were uploaded on their screen. More specifically, subjects would see a screen with three parts. ${ }^{7}$ The top of the screen contained some information regarding the time remaining before the end of the session, the cumulative number of records they had entered in real time, and information about the compensation that the participant would receive in the current session. The middle part of the screen contained the various fields in which subjects would enter the data, and the bottom of the screen contained the source data. When subjects had finished entering the relevant items regarding a particular record they were instructed to click on the "next record" button and another record would be uploaded at the bottom of the page, so they would proceed in the same manner. Note that to ensure an equal level of difficulty of the task across subjects, all subjects were presented with the same records and in the same order.

The experiment took place between November 2010 and December 2011. We recruited subjects from the student body of the University of Southampton through email announcements for an online experiment. To study possible gender effects, we targeted an equal number of males and females. In total 320 student subjects completed the experiment. ${ }^{8}$ Subjects who expressed interest in participating received log-in details from us, and upon logging in the experimental webpage they received further instructions as to how to perform the task and the form of their compensation. ${ }^{9}$ Subsequently, they were given an opportunity to practice the task to ensure that they had understood what it entails, and then started work.

The experiment was organized in four sessions, each session involving a work period of one hour. Participants could freely choose when to work, subject to the restrictions that the four sessions were to be completed within one week and that participants could perform only one session per day, by logging in between $8 \mathrm{am}$ and $10 \mathrm{pm}$. In each session, subjects would receive instructions at the beginning as to what the compensation structure would be, and then proceeded to perform the task for one hour. ${ }^{10}$ At the end of the last session we asked them to fill out a questionnaire and

\footnotetext{
${ }^{7} \mathrm{~A}$ screenshot of the task page can be found in the Appendix.

${ }^{8} \mathrm{An}$ additional 93 subjects logged in at some point but never completed the experiment. We discuss attrition in the next section.

${ }^{9}$ Experimental instructions are provided in the Online Appendix available at http://www.personal.soton.ac.uk/mv1u06/Research.html and http://sites.google.com/site/mircotonin/research.

${ }^{10}$ In each session, after instructions were given and just before the working time started we asked subjects a series of 4 questions aimed at controlling for whether subjects were tired or stressed on that particular day prior to taking the experiment. In particular, we asked the following questions: "Have you been able to concentrate on whatever you are doing? Have you lost much sleep over worry? Have you felt constantly under strain? Have you been feeling unhappy or depressed?" The answers to these questions were given on a 4 point scale ranging from 1 (Not at all), to 4 (Much more than usual). There is no systematic difference in the answers to these questions across the four groups that will be defined below.
} 
to provide their banking details, so that their compensation could be arranged. ${ }^{11}$ Finally, we also asked all subjects whether they want to donate a percentage of their total earnings to a charity of their choice. ${ }^{12}$

Subjects received $£ 20$ for completing the project. Moreover, they received additional compensation depending on the amount of bibliographic records they entered. The specific amount they would receive for each entry was announced at the beginning of each session and is described in the next subsection. To avoid inducing performance that would be motivated by future expected rewards, we told subjects that neither the piece rate nor any other aspect of a given session depended on their performance in previous sessions. Finally, subjects were instructed that they would only be paid for correct entries and only if they completed all four sessions within the allotted one-week period.

\subsection{Experimental Design}

Our experimental design involves 4 stages and 4 groups defined below and summarized in Table 1:

Group 1 (52 subjects): Subjects in this group received the baseline piece rate $(2.5 \mathrm{p}$ per correct entry) throughout the 4 sessions. This group will allow us to account for any trend in productivity across sessions due to, for instance, learning or boredom.

Group 2 (52 subjects): Subjects in this group received the baseline piece rate (2.5p) in session 1; in subsequent sessions, they worked under three different piece rates $(5 \mathrm{p} / 7.5 \mathrm{p} / 10 \mathrm{p})$, presented in random order. This group will allow us to estimate the effect of financial incentives on productivity.

Group 3 (100 subjects): Subjects in this group underwent the following treatments:

- Session 1: Subjects received the baseline piece rate (2.5p).

- Session 2 and Session 3: The following two treatments in random order:

- Treatment $A$ (TA): Subjects received the baseline piece rate (2.5p). In addition, they were told that if they wish we would make a lump-sum donation (£10) to a charity of

\footnotetext{
${ }^{11}$ The questionnaire contained questions on procedural aspects of the experiment (whether the instructions were clear, where they performed the task etc.), some questions on socioeconomic characteristics (age, gender, subject of study, work experience, engagement with charities etc.), and some open ended questions on the motivation regarding the decision of how much effort to put in the task. Table 2 summarizes demographics, while Table 3 contains summary statistics of answers to questions related to procedures.

${ }^{12}$ This last decision is analyzed in Tonin and Vlassopoulos (2013).
} 
the subject's choice among a list of charities with diverse missions. ${ }^{13}$

- Treatment $B(10 p)$ (TB10): Subjects received the baseline piece rate (2.5p). In addition, they were told that if they wish we would make a donation to their preferred charity based on their performance, with a charity piece rate of 10p per entry.

- Session 4: Treatment Choice (TC): Subjects were told that they could decide how much of a 10p per entry piece rate to keep for themselves and how much to pass on to a charity of their choice. The charity would receive double the per entry bonus they decided to pass.

Group 4 (116 subjects): Subjects in this group underwent the following treatments:

- Session 1: Subjects received the baseline piece rate (2.5p).

- Session 2 and Session 3: Two versions of Treatment B in random order: in one the charity piece rate was $5 \mathrm{p}$ (TB5), in the other the charity piece rate was 15p (TB15).

- Session 4: Treatment Choice (TC).

Groups 3 and 4 will allow us to estimate the effect of social incentives on productivity, as well as to examine productivity when subjects can choose their preferred mix of financial and social incentives. The larger sample size for these two groups is due to the fact that we expected a larger variance in the responsiveness to social incentives compared to financial incentives. Notice that in the first session all subjects worked under the baseline piece rate (2.5p), so performance in the first session provides a measure of initial productivity, which will be used in the subsequent analysis to sort them into low and high productivity subjects.

Here we provide the rationale behind the choice of parameterization of our treatments. We chose a relatively low powered baseline piece rate (2.5p per entry) to avoid the situation in which people work since the beginning at a level where the cost of effort function is very steep, i.e. close to their physical capacity, thus making it more difficult to detect further increases in effort when additional incentives are introduced. For Group 2 we chose sufficiently different piece rates (5p, 7.5p, 10p) to be able to identify their effect on performance. For Group 3, we chose the amount of $£ 10$ for the lump sum treatment and 10 p donation piece rate so that the amount the charity receives is on average similar in the two cases, while for Group 4 we chose sufficiently different

\footnotetext{
${ }^{13}$ The list of charities from which subjects could choose is provided in the Online Appendix. Note that subjects could choose not to make any donation by selecting the option "I do not wish any donation to be made". Nobody selected this option.
} 
donation piece rates ( $5 \mathrm{p}$ and $15 \mathrm{p}$ ) to be able to identify a marginal response, if any. We chose relatively generous donation piece rates as we expected them to be less effective than private piece rates in inducing additional effort.

Table 1: Summary of Experimental Design

\begin{tabular}{|c|c|c|c|c|c|c|c|}
\hline & \multirow{2}{*}{$\begin{array}{l}\text { Session } 1 \\
\text { Financial } \\
\text { Incentive }\end{array}$} & \multicolumn{2}{|c|}{ Session 2} & \multicolumn{2}{|c|}{ Session 3} & \multicolumn{2}{|c|}{ Session 4} \\
\hline & & $\begin{array}{c}\text { Financial } \\
\text { Incentive }\end{array}$ & $\begin{array}{c}\text { Social } \\
\text { Incentive }\end{array}$ & $\begin{array}{l}\text { Financial } \\
\text { Incentive }\end{array}$ & $\begin{array}{c}\text { Social } \\
\text { Incentive }\end{array}$ & $\begin{array}{l}\text { Financial } \\
\text { Incentive }\end{array}$ & $\begin{array}{c}\text { Social } \\
\text { Incentive }\end{array}$ \\
\hline Group 1 & $2.5 \mathrm{p}$ & $2.5 \mathrm{p}$ & $\varnothing$ & $2.5 \mathrm{p}$ & $\varnothing$ & $2.5 \mathrm{p}$ & $\varnothing$ \\
\hline Group 2 & $2.5 \mathrm{p}$ & $5 \mathrm{p} / 7.5 \mathrm{p} / 10 \mathrm{p}$ & $\varnothing$ & $5 \mathrm{p} / 7.5 \mathrm{p} / 10 \mathrm{p}$ & $\varnothing$ & $5 \mathrm{p} / 7.5 \mathrm{p} / 10 \mathrm{p}$ & $\varnothing$ \\
\hline Group 3 & $2.5 \mathrm{p}$ & $2.5 \mathrm{p}$ & $\begin{array}{l}\text { Lump sum } 10 \\
\text { or } \\
\text { 10p for charity }\end{array}$ & $2.5 \mathrm{p}$ & $\begin{array}{l}\text { Lump sum } 10 \\
\text { or } \\
\text { 10p for charity }\end{array}$ & Cho & \\
\hline Group 4 & $2.5 p$ & $2.5 p$ & $5 / 15 p$ to charity & $2.5 \mathrm{p}$ & $5 / 15 p$ to charity & Cho & \\
\hline
\end{tabular}

We refer to the piece rate as financial incentive, and to incentives induced by TA and TB as social incentives. Note that to ensure that subjects had understood what each of these treatments entailed in terms of compensation for them and, where relevant, for the charity, we asked them to answer a hypothetical question aimed at testing their understanding. ${ }^{14}$ Subjects could only proceed to the next stage if they provided a correct answer to the quiz.

\section{Descriptive Analysis}

Our analysis is based on a sample of 320 subjects who completed all four sessions of the experiment. In addition, 93 subjects logged in but did not complete the four sessions. Of the 93 subjects who dropped out, about two thirds, 58, did not go beyond the first session, 23 stopped after the second session, while 12 dropped out after the third session. Productivity in the first session was lower for those who dropped out after either the first, second, or third session compared to those who completed the experiment (see Table 1a in the Online Appendix). This suggests that dropping

\footnotetext{
${ }^{14}$ In particular, in treatments involving a charity, the question was posed in the following way: "If in the following 60 minutes you complete 50 entries, how much will you earn for this session? How much will the charity receive?"
} 
out is related to a lack of interest and/or low ability to perform the task..$^{15,16}$ The fact that 35 participants withdrew after the second or third session is potentially a concern as they dropped out after being exposed to treatments. However, using a Pearson's $\chi^{2}$ test (see Tables 3a and 4a in the Online Appendix), we cannot reject the null that what subjects experienced in terms of treatment(s) is independent of the decision to drop out after the second session (p-value: 0.52 ) or after the third session (p-value: 0.29) instead of completing the whole experiment.

The sample is quite balanced in terms of gender composition, with 179 female and 141 male participants. Moreover, the gender distribution is not systematically different across the four groups (Pearson $\chi^{2}$, p-value: 0.33). With regards to other key demographic characteristics, two-thirds of the subjects were born in the UK and most of the subjects (84\%) were born in the period 1987-1993, with the remaining part being older (see Table 2). Most of the subjects performed all four sessions at home $(73 \%)$, alone $(80 \%)$, and on the same computer $(77 \%)$ and found the instructions about the task and about the compensation clear and easy to follow (see Table 3).

Recall that in session 4 we asked subjects in Groups 3 and 4 to select how to split a piece rate of $10 \mathrm{p}$ between themselves and a charity of their choice. As it turned out, $52 \%$ of the subjects shared some of the piece rate with a charity, and conditional on sharing subjects gave on average $3.7 \mathrm{p}$ to the charity. Figure 1 below illustrates the pattern of sharing with a charity: as is typical in these situations involving a subject sharing an amount received from the experimenter with a third party, there is a peak at not giving anything at all and another one at sharing the amount in half. We, therefore, see that half of the subjects choose a compensation structure embedding social incentives.

In the analysis we use two definitions of productivity: number of records completed and number of records entered correctly. The correlation between these two measures is rather high, at 0.91. One interesting question that we are able to examine using these two measures of productivity is whether the introduction of financial or social incentives has a differential effect on the quantity and quality of output. Note that our definition of a correct entry is a strict one - we treat a record entry as correct if it contains absolutely no mistake. As a robustness check, we also experimented

\footnotetext{
${ }^{15}$ Moreover, those who dropped out after the second or third sessions started the second session later than those who completed (average difference: 0.51 days, t-test p-value: 0.014 ). This implies that they had less time to complete all four sessions and were thus more likely to drop out. For instance, $40 \%$ of those not completing started the second session on the last possible day, compared to just $16 \%$ of those completing. Therefore, running out of time is most likely an important factor behind dropping out by many of these participants. Notice that at the stage of deciding when to start session 2 participants were not yet exposed to treatments.

${ }^{16}$ One could think that low-productivity subjects may be more likely to drop out from Group 1 compared to other groups as they do not experience any change in their pay scheme. However, in Table 2a in the Online Appendix we look at whether first session productivity differs across groups and find no significant differences between Group 1 and the other groups.
} 


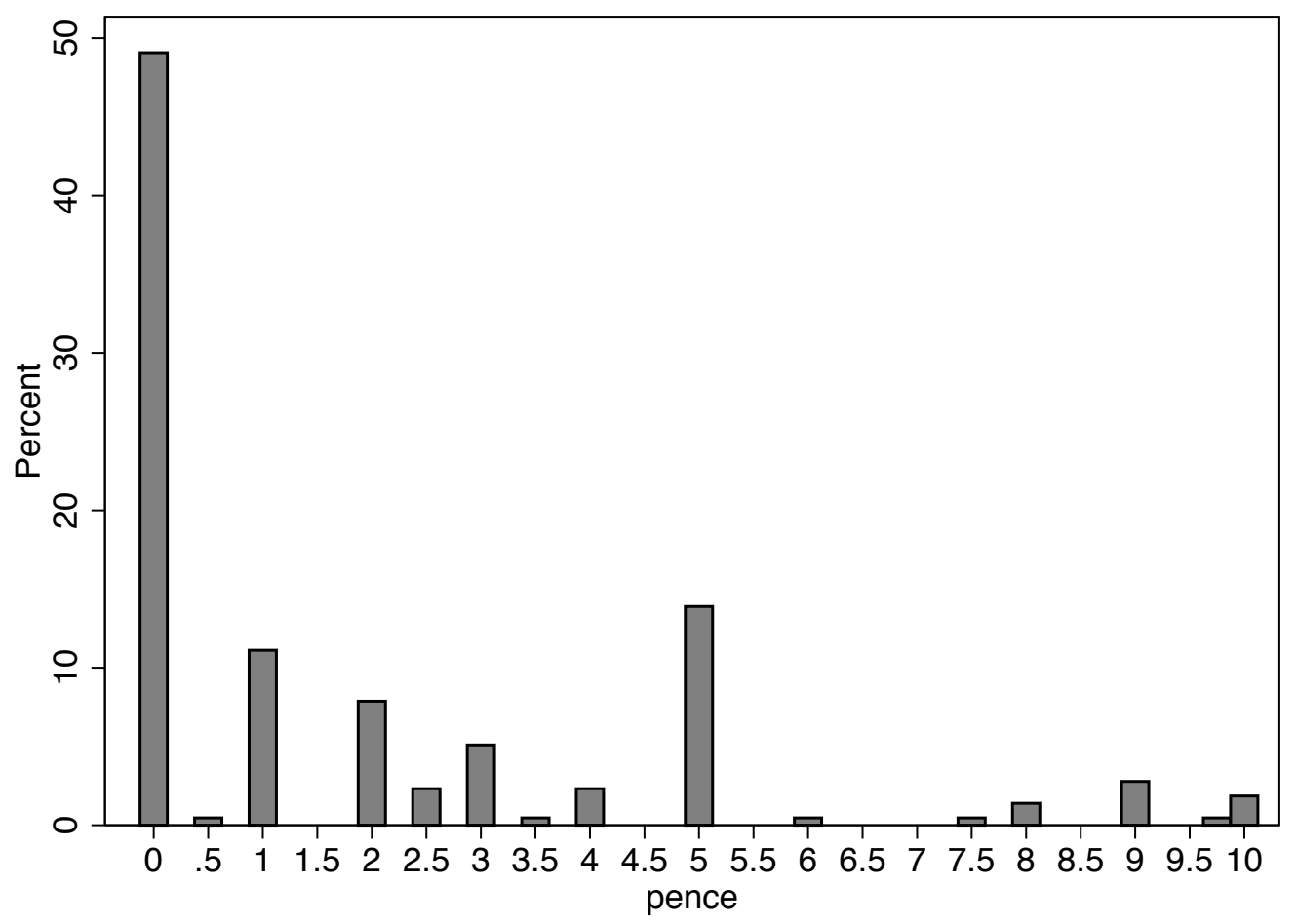

Figure 1: Piece rate passed on to charity

with using an alternative less strict definition of what constitutes a correct entry and the results, available upon request, are very similar in terms of significance and magnitude to what we present here. ${ }^{17}$

To obtain a first glance of the subjects' performance, Figure 2 summarizes unconditional average productivity in each of the four sessions separately for each group. In the first session subjects entered on average 89 records (SD 28). Of those 89 records, 82 are correct indicating that on average less than $10 \%$ of entries were incorrect. In the first session, Group 2 appears to be slightly more productive than the other three groups, but pairwise Mann-Whitney tests fail to reject equality of distributions of correct entries at conventional levels. ${ }^{18}$ Looking also across the rest of the sessions, average performance seems not to vary much for Group 1, while subjects in the other groups appear to be raising productivity in sessions 2 to 4, with Group 2 in particular showing the sharpest increase.

\footnotetext{
${ }^{17}$ In particular, in our alternative definition we classify as correct entries that do not contain a mistake in more than one field, and if a mistake occurs it does not involve a discrepancy of more than 8 characters.

${ }^{18}$ Average productivity (correct entries) is $82.2,85.0,78.1,83.5$ in Groups $1-4$ respectively. The $p$-value for the test comparing Group 1 and 2 is 0.51 , for comparison of Group 1 and 3 is 0.32 , for comparison of Group 2 and 3 is 0.10, for comparison of Group 1 and 4 is 0.90, for comparison of Group 3 and 4 is 0.15 and for comparison of Group 2 and 4 is 0.55 . The corresponding p-values for the Kolmogorov-Smirnov test are 0.91, 0.53, 0.17, 0.83, 0.08, and 0.55.
} 


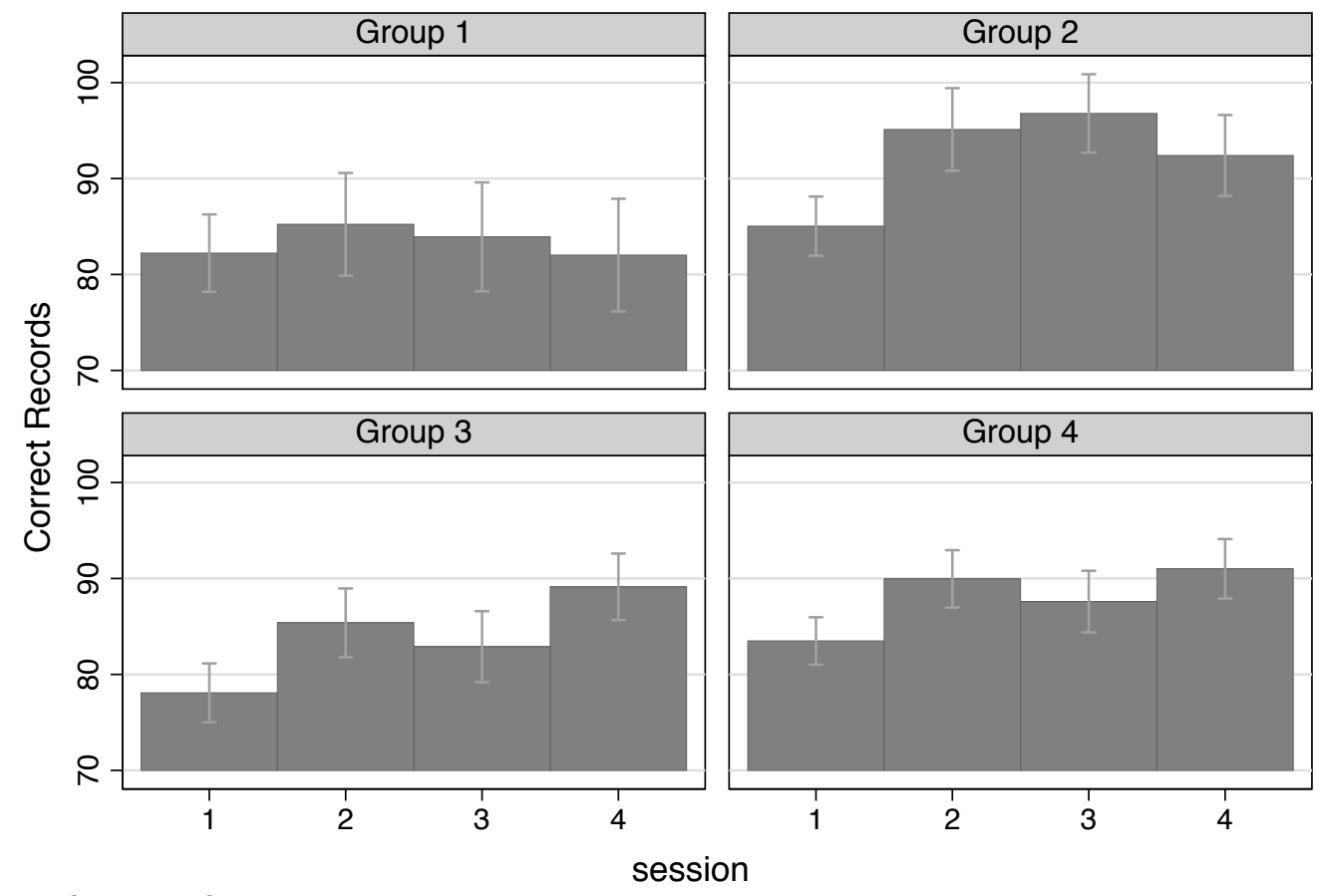

Graphs by Group

Figure 2: Average Productivity (standard error bars) in each session across groups - All

We also check whether subjects differ in terms of productivity depending on whether or not they choose to be in an environment with social incentives when given the opportunity in the Choice treatment. We find no difference in terms of baseline (i.e. session 1) productivity as measured by the number of completed entries ( $\mathrm{M}-\mathrm{W}$ test $\mathrm{p}$-value: 0.86 ), the number of correct entries (M-W test p-value: 0.88 ), or the ratio between correct and completed entries ( $\mathrm{M}-\mathrm{W}$ test p-value: 0.94 ).

Note that these unconditional averages give an incomplete picture of the various treatment effects of interest, as they do not control for individual characteristics and in addition pool together subjects who are exposed to different treatments (for Groups 2-4 and in session 2 onwards). To address these issues, we next turn to regression analysis. 


\section{Regression Analysis}

Our regression analysis consists of estimating panel data specifications of the form:

$$
\begin{aligned}
\Delta y_{i s}= & \theta_{i}+\beta_{1} P R 5_{i s}+\beta_{2} P R 7.5_{i s}+\beta_{3} P R 10_{i s}+\gamma T A_{i s}+\delta_{1} T B 5_{i s}+\delta_{2} T B 10_{i s} \\
& +\delta_{3} T B 15_{i s}+\lambda T C_{i s}+\sum_{s=2}^{4} \eta_{s} S_{s}+\epsilon_{i s},
\end{aligned}
$$

where $\Delta y_{i s}$ is percentage change in productivity of individual $i$ in session $s$ relative to session $1 .{ }^{19}$ Our primary interest is thus in the effects of incentives on the relative change in own productivity. However, because the average percentage change in productivity does not generally coincide with another potentially interesting measure, the average change in absolute productivity, in section 4.4 we also consider absolute productivity as the dependent variable. Individual fixed effects $\theta_{i}$ capture time-invariant determinants of productivity at the individual level and $P R 5, P R 7.5, P R 10$ are dummies for the different piece rates faced by subjects in Group 2. TA, TB5, TB10, TB15 and $T C$ are dummies for treatments $A$, the three versions of $B(5 \mathrm{p} / 10 \mathrm{p} / 15 \mathrm{p})$ and $C h o i c e$ respectively, while $S_{s}$ are session fixed effects that capture trends in productivity. The coefficients of main interest are $\beta_{1}, \beta_{2}, \beta_{3}$, which measure the responsiveness of subjects' productivity to variations in the piece rate, and $\gamma, \delta_{1}, \delta_{2}$ and $\delta_{3}$, which indicate the responsiveness of subjects' productivity to social incentives. In particular, $\gamma$ measures the response to a lump sum donation that is not contingent on performance, while the other three coefficients measure the response to a performancecontingent donation. Comparison of $\beta_{1}, \beta_{2}$, and $\beta_{3}$, and of $\delta_{1}, \delta_{2}$ and $\delta_{3}$ will determine whether effort is sensitive to the "strength" of private and social incentives, respectively. Finally, $\lambda$ measures the productivity response in the Choice treatment where participants can choose their preferred mix of financial and social incentives.

It is worth noting here that our experimental design has the convenient feature that it allows for estimation of the parameters of interest in equation (1) using either a within-subject analysis, by making use of all 4 sessions, or a between-subject analysis, by restricting attention to sessions 1 and 2. In what follows we first present results making use of all the data that we have available and then proceed to present the between-subject analysis to reassure that results are robust and are not driven by interdependencies across treatments that may be present in the within-subject design.

\footnotetext{
${ }^{19}$ All subjects entered a positive number of completed entries in session 1, while 1 subject has 0 correct entries in all four sessions. In the regression results presented we omit this subject when we look at correct entries. The results do not change if we instead treat this subject as having a $0 \%$ productivity change in all sessions.
} 
Standard errors are clustered at the individual level in all specifications where data from more than 2 sessions are used.

\subsection{Results for the Whole Sample}

Table 4 presents results for both measures of productivity - correct and completed number of entries. A first point of interest is to examine what is the productivity trend across the four sessions. Restricting the analysis to observations from Group 1, columns (1) and (2) of Table 4, what we see is a small decline in productivity over time, which is however not significant. This suggests that, while some learning may have taken place, absent any additional incentive, subjects' enthusiasm on performing the task waned over time. This pattern is not that surprising given that the task was tedious and repetitive.

Using observations from Groups $1 \& 2$, columns (3) and (4) of Table 4, allows us to provide an estimate of the responsiveness of output to changes in the private piece rate, net of any productivity trend. What we see is that productivity increases as financial incentives get stronger. Doubling the piece rate from $2.5 \mathrm{p}$ to $5 \mathrm{p}$ increases productivity by almost $10 \%$, albeit the coefficient is not statistically significant. Further increasing the piece rate to $7.5 \mathrm{p}$ gives an additional boost to productivity ( $14 \%$ for completed, $17 \%$ for correct, both statistically significant), while there is no further improvement when moving from $7.5 \mathrm{p}$ to $10 \mathrm{p} .^{20}$

Columns (5) and (6) of Table 4 present results when we pool observations from all groups. The coefficients on TA and the three different TBs allow us to estimate the effect of social incentives. These coefficients are generally statistically significant and of the same magnitude. ${ }^{21}$ In particular, sessions where subjects are exposed to social incentives are associated with a rise in productivity that ranges from $9 \%$ to $17 \%$ ( $12 \%$ to $14 \%$ for completed), but is not always precisely estimated. When we estimate a specification where TA and the three TBs are collapsed into one treatment, represented by the dummy variable Treat (bottom of Table 4) we find a statistically significant productivity increase of $13 \%$. What emerges, then, is that social incentives are effective in motivating subjects to supply higher effort, but that the specific form (lump sum or related to performance) or strength (5p, 10p, 15p donation piece rate) of these incentives do not appear to matter. Of course, we do not know what would happen if social incentives that were much more generous or much less

\footnotetext{
${ }^{20}$ Pairwise comparison (Wald test) of the coefficients on the piece rate dummies (correct entries) produces the following: PR5 vs PR7.5 (p-value=0.10); PR7.5 vs PR10 (p-value=0.51); PR5 vs PR10 (p-value=0.005). Results are similar for completed entries.

${ }^{21}$ Performing a series of pairwise Wald tests, we fail to reject the null hypothesis that the coefficients are indeed identical.
} 
generous were offered. For instance, a very low donation might have been completely ineffective or could even backfire if subjects find it paltry.

This result of insensitivity to the form and size of social incentives is consistent with the findings in Tonin and Vlassopoulos (2010), which compare a lump sum donation to one contingent on productivity, and is also in line with experimental evidence regarding the efficiency of matching grants in raising charitable giving. For instance, Karlan and List (2007) find that matching increases giving but tripling the matching rate does not have additional impact, while Huck and Rasul (2011) even find a decrease in actual donations given as the matching rate increases from 0 to 0.5 and 1 . In our context, the donation piece rate could be interpreted as a matching grant, linking a unit of extra effort to donations at a different rate. The finding of a flat response to social incentives indicates that the desire to affect the amount received by the charity (i.e. so called pure altruism) is not the motivational driver behind the increase in productivity, nor is a desire to maximize the total amount paid to both subject and charity (i.e. so called efficiency concern). Our interpretation is that social incentives are instrumental in changing the perceived nature of the job, from a standard job to a job with a social component, thus enhancing the identification between the job and the workers, an aspect that is emphasized as being an important determinant of workers' effort in organizations by Akerlof and Kranton (2005).

It is also of interest to compare the impact of incentive schemes that are chosen by subjects (as in our Choice treatment) to the impact of exogenously imposed compensation schemes. In particular, we can see that the productivity effect in the Choice treatment, where subjects can choose to allocate 10p between themselves and a charity, is larger than both TB10, where a charity is exogenously allocated 10p, and PR10, where the piece rate is fixed at $10 \mathrm{p} .{ }^{22}$ This result echoes Charness et al. (2012) who find that delegating the wage decision to workers increases effort in a gift exchange experiment. In terms of cost, notice that the average total piece rate paid on the Choice treatment is $12 \mathrm{p}$, as subjects donate on average $20 \%$ of $10 \mathrm{p}$, which is doubled by us, so that on average participants receive $8 \mathrm{p}$ piece rate and the charity $4 \mathrm{p}$. Therefore, the cost of the Choice treatment is a bit higher than PR10 (10p) and similar to the cost of TB10 (12.5p). This suggests that firms willing to introduce corporate giving programmes may consider giving employees the opportunity to "opt in". As mentioned in the introduction, this is indeed what takes place with schemes like payroll giving or workplace giving. In the UK, for instance, many firms give the opportunity to employees to make tax-free donations to their chosen charities, often with

\footnotetext{
${ }^{22}$ We can reject the null that Choice and TB10 are identical: the p-value of a Wald test is 0.04 for completed and of 0.06 for correct. When comparing Choice to PR10 the test yields a p-value of 0.099 for completed and 0.26 for correct.
} 
matched employee contributions. According to figures by the Payroll Giving Centre, in 2011/12 more than 735,000 employees participated in the scheme, ${ }^{23}$ while in the US a survey by the Center on Philanthropy at Indiana University (undated) finds that in 2008-2009 36\% of full-time employees worked at a company offering some type of workplace giving campaign, with $54 \%$ of those asked to give actually donating.

As a robustness check for these results, columns (7) and (8) of Table 4 report the results when we limit the analysis to observations obtained from sessions 1 and 2. This specification uses only the between-subject variation - it is essentially a difference-in-differences estimation - to identify the parameters in equation (1). ${ }^{24}$ That is, the between-subject analysis provides estimates of the parameters of interest using information up to the point where subjects have been exposed to at most one change in the compensation they face, compared to the baseline condition of being paid a 2.5p piece rate. Reassuringly, the magnitudes of the estimated parameters are very similar to the ones using all four sessions. ${ }^{25}$ This provides some confidence that the results are not driven by interdependencies across treatments.

We also perform two additional robustness checks to see whether the estimated responses to the incentives are affected by the order in which the subject is exposed to the various treatments. First, we add to equation (1) interactions between the dummies for social incentives and the dummy for session 3 , and find the resulting coefficients not to be statistically significant. Second, we add a dummy for experiencing an increase in the piece rate in a given session compared to the previous session for Group 2, which also turns out not to be significant.

The results so far indicate that both financial and social incentives are quite effective in boosting productivity. It should be noted though that, from the point of view of the employer's profitability, these productivity responses will reduce unit labor costs only if fixed labor costs are sufficiently high.

In order to better understand who is mostly affected by incentives, in what follows we perform some subgroup analysis.

\footnotetext{
${ }^{23}$ www.payrollgivingcentre.com/facts figures.htm [consulted on 22 June 2012].

${ }^{24}$ We cannot estimate $\lambda$, the parameter associated with the Choice treatment, as this treatment was introduced in the last session.

${ }^{25}$ Also in this case, by performing a series of pairwise Wald tests, we fail to reject the null hypothesis that the effects of the various types of social incentives are identical.
} 


\subsection{Productivity Split}

We examine whether there are differences in the response to incentives for subjects with different ability (or motivation) to perform the data entry task at hand. To this end, we split our sample into high productivity (above median) and low productivity (below median) subjects based on their performance (number of correct entries) in session 1, that is, before the introduction of social incentives or variations in the private piece rate. ${ }^{26}$

Figures 3 and 4 illustrate average productivity in each of the four sessions by group, separately for high and low productivity subjects. What emerges from Figure 3 is that the productivity of low productivity subjects remains flat (Group 1), while adding financial (Group 2) or social (Groups 3 and 4) incentives appear to improve performance. On the other hand, Figure 4 illustrates that high productivity subjects actually display some learning and improve their performance even in the absence of incentives (Group 1).

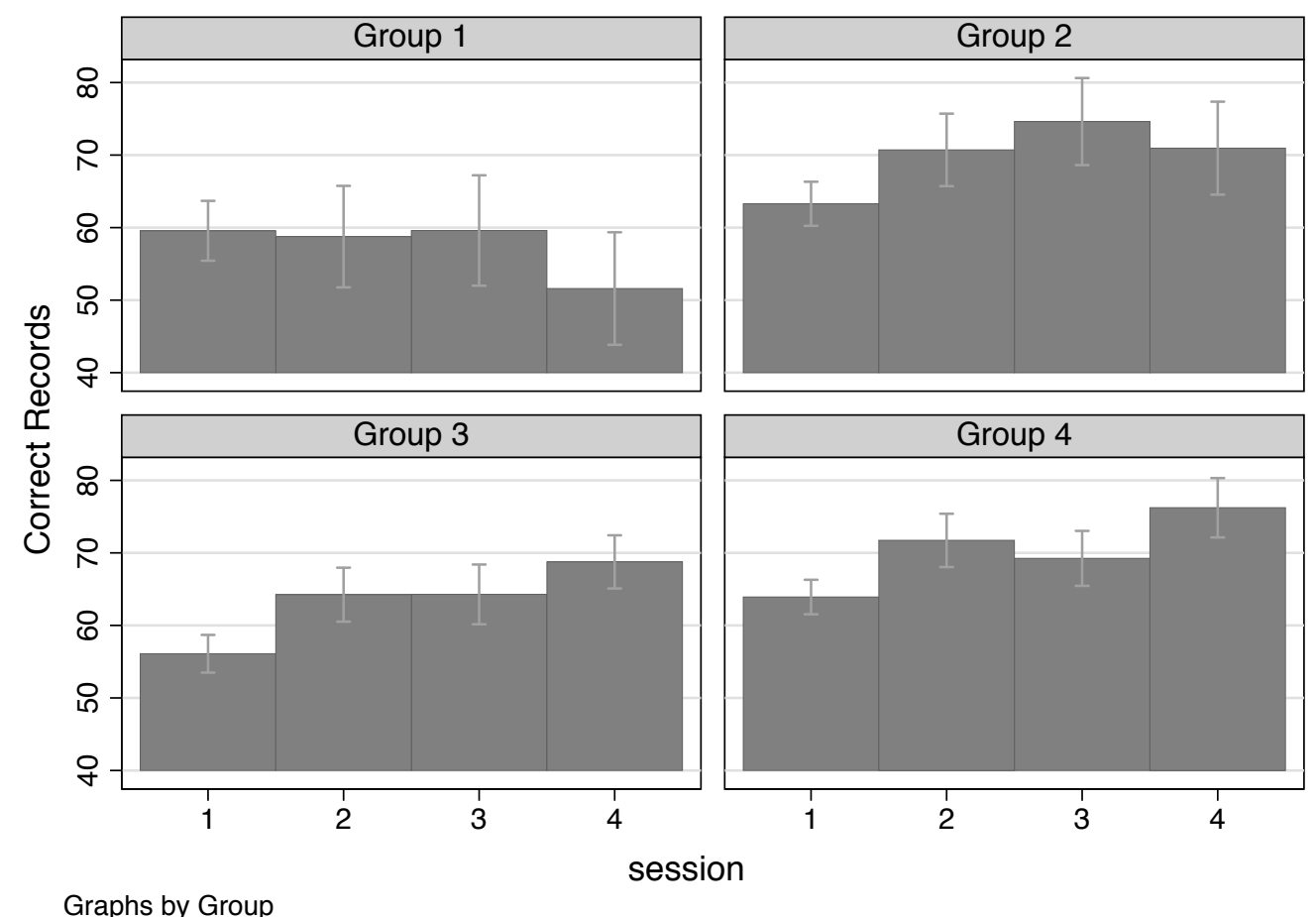

Figure 3: Average Productivity (standard error bars) in each session across groups - Low Productivity

To determine the size and significance of the relative change of performance due to the various

\footnotetext{
${ }^{26}$ In the high (low) productivity group there are 27 (25) subjects from Group 1, 31 (21) from Group 2, 46 (54) from Group 3, and 58 (58) from Group 4.
} 
incentives under investigation, we next turn our attention to regression results in Table 5, where we estimate equation (1) separately for the low and high productivity groups.

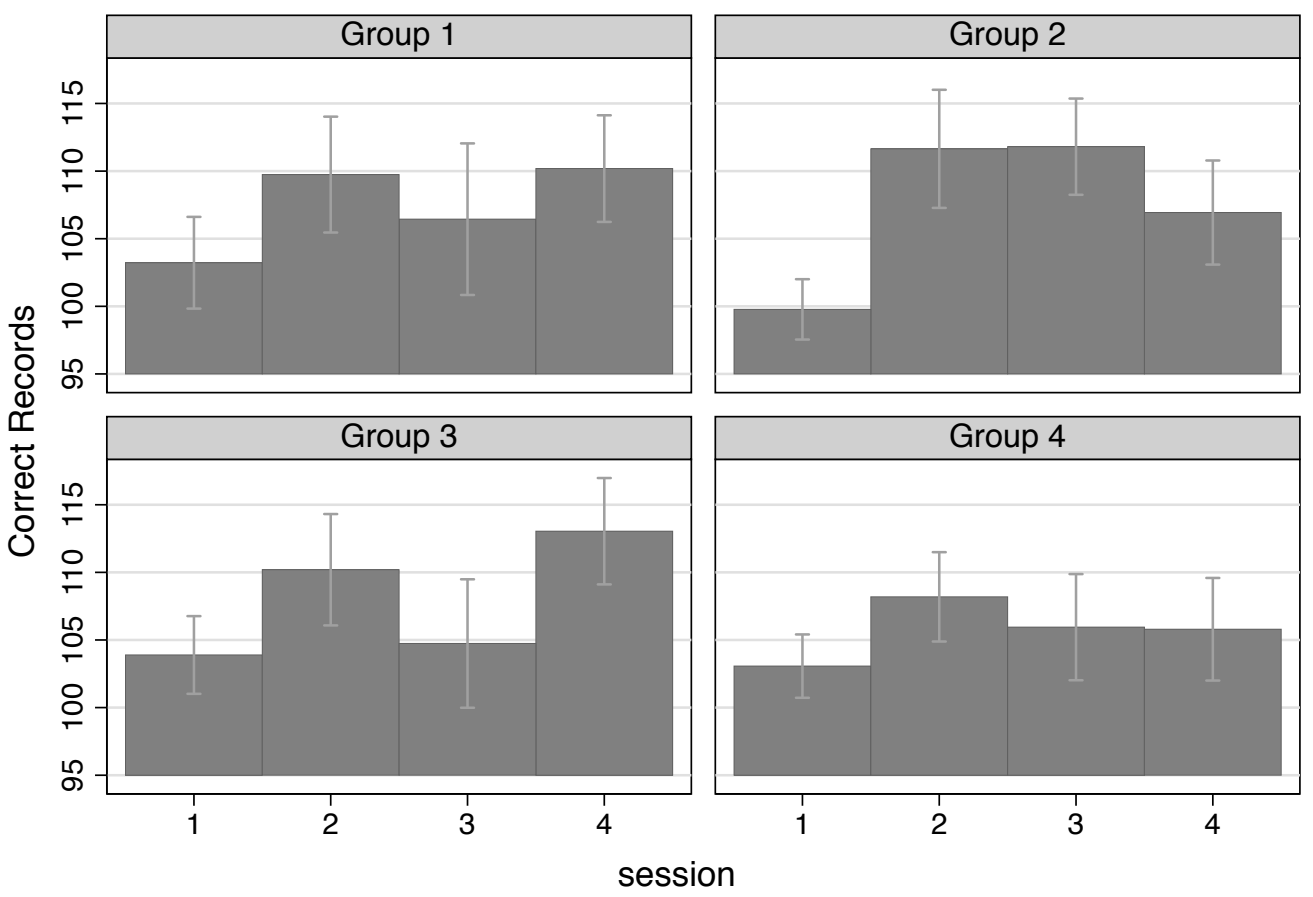

Graphs by Group

Figure 4: Average Productivity (standard error bars) in each session across groups - High Productivity

A very interesting pattern emerges from this analysis: low productivity subjects (columns 1 and 2 in Table 5) are very responsive to both financial and social incentives, while high productivity subjects (columns 3 and 4 in Table 5) are not responsive to incentives of any kind. ${ }^{27}$ Again, for the low productivity subgroup, the coefficients measuring the impact of social incentives are not statistically different from each other. Looking at the session dummies, one can confirm the pattern highlighted in the figures above that high productivity subjects display some evidence of a positive trend, in particular in the second session, possibly because of some learning. On the other hand, the trend is negative for low productivity subjects, with productivity in the last session being $20 \%$ lower than in the first session. Thus, it seems that high productivity subjects start at a high level and keep that level (or slightly improve) even without additional incentives, while low productivity subjects start at a low level and drop even further if no additional incentives are provided. This suggests that the initial difference in productivity between the two groups is not mostly due to their

\footnotetext{
${ }^{27}$ The same overall picture emerges if we use completed entries instead of correct tables to define the two groups. The two definitions are very overlapping, with only 22 subjects switching between the high and low productivity groups when changing the measure of productivity.
} 
skills (e.g. their ability to type), or their equipment (e.g. the speed of their internet connection). If this were the case, then we would expect a similar productivity trend across the two groups. Instead, subjects with productivity above and below the median in the first session most likely differ in terms of their motivation to perform the job, with high productivity subjects being highly motivated individuals. For these individuals, there is probably little room to further improve productivity, and, therefore, they appear not to respond to incentives. Instead, both financial and social incentives work very well in motivating those who need to be motivated, that is, the low productivity (i.e. low motivation) subjects. ${ }^{28}$ This subgroup is of particular interest, as eventually, perhaps after 20 hours of entering bibliographical records, we would expect that almost everyone would need a boost to their motivation to work.

Using these estimates, it is possible to compare quantitatively financial and social incentives for low productivity subjects. In particular, we can compare the effect of increasing the piece rate by $5 \mathrm{p}$, from $2.5 \mathrm{p}$ to $7.5 \mathrm{p}$, as captured by the coefficient on PR7.5, to the effect of introducing a charity piece rate of 5p, as captured by the coefficient on TB05. The financial incentive increases productivity by more than the equally expensive social incentive (30\% vs. $27 \%$ for completed, $31 \%$ vs. $23 \%$ for correct), but the difference is not statistically significant (Wald test p-value completed: 0.73, correct: 0.45 ). Finally, also in this case we see a higher increase in productivity associated with the Choice Treatment as compared to PR10 and TB10. ${ }^{29}$ This result indicates that the most significant productivity reaction can be obtained not when charitable donations are taxed out of workers' earnings by the employer but rather when subjects have some discretion as to whether their earnings will be shared with a charity.

\subsection{Volunteering Split}

In order to obtain a measure of prosocial motivation outside the context of the experiment, we collected information on whether participants have done any voluntary work for a charity in the previous 12 months. The response to this question splits the sample into roughly two equally sized groups, one which reported to have no volunteer experience $(55.6 \%)$ and another that reports to have volunteered at least once $(44.4 \%)$. The two groups are not different in terms of initial productivity, with volunteers entering 91.5 (84.5 correct) records and non-volunteers entering 86.8 (79.8 correct) records (MW test of difference p-value $=0.20$ for completed and 0.16 for correct).

\footnotetext{
${ }^{28}$ Falk and Ichino (2006) also find evidence that the positive impact of peer pressure on productivity is larger at low productivity levels.

${ }^{29}$ The p-values of pairwise Wald tests for completed (correct) records are: Pr10-Choice: 0.14 (0.17), TB10-Choice: 0.07 (0.07).
} 
In Table 6, we present results of the baseline specification separately for these two groups. What we see here is evidence of different responsiveness to social incentives for the two groups. For volunteers, the coefficients on the social incentive dummies are large and in some cases statistically significant. In particular, when we collapse the social incentive treatments into one dummy at the bottom of the table we see that social incentives are associated with a 16-17\% increase in productivity. For the group without volunteer experience on the other hand, the productivity effects of social incentives are small in magnitude and never significant. We do see therefore some evidence of behavior in the experiment being correlated with a self-reported measure of prosocial attitude outside of the experiment.

\subsection{Absolute Productivity}

So far we have presented results that focus on the effects of incentives on the relative change in own productivity, expressed as the percentage change compared to initial productivity. Given our focus on the effect of incentives on individual motivation, this is our main object of interest as it allows to estimate the proportional change in productivity arising from various types of incentives. Nevertheless, it is also of interest to look at the absolute change in productivity.

In Table 7, we present results for a specification as in (1) where the dependent variable is the number of entries, either completed or correct. What emerges is that increasing the piece rate to $7.5 \mathrm{p}$ or $10 \mathrm{p}$ increases the number of entries by around 10, with low productivity subjects increasing by around 15 and high productivity not reacting much. We also see a significant increase in absolute productivity associated with the Choice treatment both for the whole sample (around 10) and the low productivity subsample (around 20). When we look at social incentives, there is some evidence of an increase of around 10 in the number of completed entries for low productivity subjects, while the smaller increase in the number of correct entries is not statistically significant. Thus, when looking at absolute rather than relative changes in productivity the effect of social incentives is more muted. This is related to the fact, already evident from the analysis in section 4.2, that incentives are particularly effective in motivating those lacking an intrinsic interest in performing well on the job and, thus, displaying a relatively low absolute initial performance.

\subsection{Accuracy}

In our experiment subjects can direct their effort towards two types of activity: one is to enter as many records as possible (quantity), the other is to ensure that these entries are correct (quality). 
As we tell subjects from the very beginning that their compensation will be based on correct entries, there is no inherent trade-off between quantity and quality, still, subjects need to decide how to allocate their effort between entering data and checking their accuracy. Notice that during the session subjects receive continuous feedback on the number of completed entries, which is displayed on the screen, but not on the number of correct entries, which is revealed only at the payment stage, after all four sessions have been completed. This means that subjects could check the quantity they produce very easily, while they cannot observe the quality of what they produce.

Here we examine whether incentives have an impact on the "accuracy" of subject's work, defined as the number of correct entries divided by the number of completed entries. In production processes where the cost of mistakes is very high, this ratio is most likely of primary interest. In Table 8 we report results for the whole sample as well as for the high and low productivity subsamples. The dependent variable is "accuracy", as defined above. What we see is that there is no significant trend across sessions, with some indication of an improvement by low productivity subjects, and that introducing social incentives does not have any effect on accuracy. With regards to financial incentives, there is evidence that a higher piece rate improves accuracy, but only for high productivity workers. Thus, while social incentives are successful in boosting productivity, they do not appear to have an impact on the degree of precision with which the task is executed. ${ }^{30}$

\subsection{Gender Differences}

This subsection examines gender difference in responses to incentives and choice of compensation patterns, in light of the recent interest and experimental evidence of gender differences in social preferences (Croson and Gneezy, 2009). What we find is that women appear to be more likely to choose an environment with social incentives: $58 \%$ of women give and give on average $3.9 \mathrm{p}$, while only $43 \%$ of men give and give on average $3.4 \mathrm{p}$. In fact, a Mann-Whitney test indicates that the there is a statistically significant difference in the sharing distribution across genders $(p$-value $=0.012)$.

When we look at gender specific differences in responses to financial and social incentives by adding to equation (1) interactions of the various treatments with a gender dummy, we find that men are more responsive to the financial incentive, ${ }^{31}$ but there are no differences in the response

\footnotetext{
${ }^{30}$ Linardi and McConnell (2011) also find that the social environment increases the quantity without affecting the quality of voluntary labor contributions.

${ }^{31}$ Notice that average productivity in the first session is similar among men and women. Men enter on average 91 records, of which 84 are correct. Women enter on average 87, of which 80 are correct. We cannot reject the null that average productivity or the distribution of productivity in the first session is the same among men and women
} 
to social incentives. Therefore, what we see is that on one hand women are more likely to choose an environment associated with a social benefit at a personal financial cost, but on the other hand, when exogenously placed in such a position, they are not more responsive than men.

\section{Discussion and Concluding Remarks}

Social incentives are pervasive in organizations in the public and nonprofit sector and are becoming increasingly a feature in the private sector through firms' engagement in CSR policies. This paper estimates a significant impact of social incentives on subjects' performance on an online data entry task. Our results that half of the subjects are ready to sacrifice some of their private compensation to increase social compensation provides empirical support for the growing recognition that some workers have an interest in advancing social causes through their effort.

As in any experimental setting, or more generally in any empirical research (Falk and Heckman, 2009), there is of course a concern about the generalizability of the results. One important concern is the fact that participants are university students and therefore not representative of the general population. In the context of our experiment, two things need to be pointed out. The first one is that several studies have documented how non-students are generally more prosocially inclined than students (see for instance Falk et al., 2013; Cappelen et al., 2011; Belot et al., 2010) and, therefore, our results may represent a lower bound estimate of the effect of social incentives for the population in general. The second thing is that the student population may actually be of particular interest as companies compete to attract the brightest graduates, for instance, by participating in recruitment fairs at universities, and the fact that a CSR policy may represent an advantage in this contest is an issue that the business literature mentioned in the introduction has highlighted. Regarding this last point, it is reassuring that students participating in experiments have been found to be similar to the rest of the student population in terms of their prosocial preferences (Falk et al., 2013; Cleave et al., 2013), though there is some evidence that students who opt to participate in an experiment report of having volunteered more time outside the lab than non-participants (Slonim et al., 2013).

Our results indicate that social incentives may be less effective than financial incentives in motivating workers, but the difference is not as large as one might have expected. A sufficient degree of tax incentives, or sufficient additional advantages coming from customers, regulators, or

(for completed entries: $\mathrm{t}$-test $p$-value $=0.12, \mathrm{MW}$ test $p$-value $=0.22$; for correct entries: $\mathrm{t}$-test $p$-value $=0.30, \mathrm{MW}$ test $p$-value $=0.53)$. 
investors, would make social incentives comparable to financial incentives. Also, one could expect social incentives to become increasingly more effective in motivating employees relative to financial incentives as earnings increase and the marginal utility of money decreases. This may be one of the reasons behind the increasing importance of CSR policies. For instance, in a survey (Economist Intelligence Unit, 2007), 34\% of corporate executives indicated that CSR was a high or very high priority for their firms three years earlier, compared to $55 \%$ saying so with regard to the present and almost $70 \%$ expressing their expectations on how high a priority it will be three years hence. Social incentives may be particularly useful also in environments where financial incentives are more difficult to implement or may have detrimental effects, for instance in teams (Fuster and Meier, 2010). This aspect deserves to be explored in future research.

\section{References}

[1] Abeler, J., Falk, A., Goette, L. and Huffman, D. (2011): Reference Points and Effort Provision, American Economic Review, 101(2), 470-92.

[2] Altmann, S., Falk, A., and Wibral, M. (2012): Promotions and Incentives: The Case of MultiStage Elimination Tournaments, Journal of Labor Economics, 30(1), 149-174.

[3] Akerlof, G., and Kranton, R. (2005): Identity and the Economics of Organizations, Journal of Economic Perspectives, 19(1), 9-32.

[4] Ariely, D., Bracha, A., and Meier, S. (2009): Doing Good or Doing Well? Image Motivation and Monetary Incentives in Behaving Prosocially, American Economic Review, 99(1), 544-55.

[5] Bandiera, O., Barankay, I., and Rasul, I. (2005): Social Preferences and the Response to Incentives: Evidence from Personnel Data, Quarterly Journal of Economics, 120(3), 917-962.

[6] Belot, M., Duch, R., and Miller, L. (2010): Who should be called to the lab? A comprehensive comparison of students and non-students in classic experimental games, Discussion Papers 2010-001, University of Oxford.

[7] Benabou, R., and Tirole, J. (2010): Individual and Corporate Social Responsibility, Economica, 77(305), 1-19.

[8] Besley, T., and Ghatak, M. (2005): Competition and Incentives with Motivated Agents, American Economic Review, 95(3), 616-636. 
[9] Brekke, K. and Nyborg, K. (2008): Attracting responsible employees: Green production as labor market screening, Resource and Energy Economics, 30(4), 509-526.

[10] Cappelen, A., K. Nygaard, E., Srensen and Tungodden, B. (2011): Social Preferences in the Lab: A Comparison of Students and a Representative Population, CESifo Working Paper Series 3511.

[11] Casadesus-Masanell, R., M. Crooke, F. Reinhardt, and Vasishth, V. (2009): Households' Willingness to Pay for Green Goods: Evidence from Patagonia's Introduction of Organic Cotton Sportswear, Journal of Economics and Management Strategy, 18(1), 203-233.

[12] Center on Philanthropy (undated): Next Generation Workplace Campaigns - Executive Summary, www.philanthropy.iupui.edu/workplacegiving.

[13] Charness, G., Cobo-Reyes, R., Jimnez, N., Lacomba, J, and Lagos, F. (2012): The Hidden Advantage of Delegation: Pareto Improvements in a Gift Exchange Game, American Economic Review, 102(5): 2358-79.

[14] Charness, G., and Kuhn, P. (2011): Lab Labor: What Can Labor Economists Learn in the Lab?, Handbook of Labor Economics, Volume 4a, 229-330.

[15] Cleave, B. L., N. Nikiforakis, and Slonim, R. (2013): Is There Selection Bias in Laboratory Experiments? Experimental Economics, 16(3), 372-382.

[16] Croson, R., and Gneezy, U. (2009): Gender Differences in Preferences, Journal of Economic Literature, 47(2), 1-27.

[17] Delfgaauw, J., and Dur, R. (2007): Signaling and Screening of Workers' Motivation, Journal of Economic Behavior and Organization, 62(4), 605-624.

[18] Delfgaauw, J., and Dur, R. (2008): Incentives and Workers' Motivation in the Public Sector, Economic Journal, 118(525), 171-191.

[19] Dohmen, T., and Falk, A. (2011): Performance Pay and Multi-Dimensional Sorting: Productivity, Preferences and Gender, American Economic Review, 101(2), 556-590.

[20] Economist Intelligence Unit (2007): Global Business Barometer.

[21] Elfenbein, D. W., and McManus, B. (2010): A Greater Price for a Greater Good? Evidence That Consumers Pay More for Charity-Linked Products, American Economic Journal: Economic Policy, 2(2), 28-60. 
[22] Evans, W.R, and Davis, W. D. (2011): An Examination of Perceived Corporate Citizenship, Job Applicant Attraction, and CSR Work Role Definition, Business $\mathcal{E}$ Society, 50(3), 456-480.

[23] Falk, A., and Heckman, J. (2009): Lab Experiments Are a Major Source of Knowledge in the Social Sciences, Science, 326(5952), 535-538.

[24] Falk, A., and Ichino, A. (2006): Clean Evidence on Peer Effects, Journal of Labor Economics, $24(1), 39-57$.

[25] Falk A., S. Meier, and Zehnder, C., (2013): Do Lab Experiments Misrepresent Social Preferences? The case of self-selected student samples, Journal of the European Economic Association, 11(4), 839-852.

[26] Fehrler, S., and Kosfeld, M. (2014): Pro-Social Missions and Worker Motivation: An Experimental Study, Journal of Economic Behavior and Organization, 100(4), 99-110.

[27] Francois, P. (2000): 'Public Service Motivation' as an Argument for Government Provision, Journal of Public Economics, 78(3), 275-299.

[28] Francois, P. (2007): Making a Difference, RAND Journal of Economics, 38(3), 714-732.

[29] Fuster, A. and Meier, S. (2010): Another Hidden Cost of Incentives: The Detrimental Effect on Norm Enforcement, Management Science, 56(1), 57-70.

[30] Gneezy, A., Gneezy, U., Nelson, L.D., and Brown, A. (2010): Shared social responsibility: A field experiment in Pay-What-You-Want pricing and charitable giving, Science, 329, 325-327.

[31] Gneezy, A., Gneezy, U., Riener, G., and Nelson, L. D. (2012): Pay-what-you-want, identity, and self-signaling in markets, Proceedings of the National Academy of Sciences, 109(19), 72367240.

[32] Gneezy, U., and Rey-Biel, P. (2014): On the Relative Efficiency of Performance Pay and Social Incentives, Journal of the European Economic Association, 12(1), 62-72.

[33] Grant, A., and Berg, J. (2011): Prosocial motivation at work: When, why, and how making a difference makes a difference, Oxford Handbook of Positive Organizational Scholarship, edited by K. Cameron, G. Spreitzer, 28 - 44.

[34] Gregg, P., Grout, P. A., Ratcliffe, A., Smith, S., and Windmeijer, F. (2011): How important is pro-social behaviour in the delivery of public services?, Journal of Public Economics, 95(7-8), 758-766. 
[35] Huck, S. and Rasul, I. (2011): Matched fundraising: Evidence from a natural field experiment, Journal of Public Economics, 95, 351-362.

[36] Imas, A. (2014): Working for the warm glow: On the benets and limits of prosocial incentives, Journal of Public Economics, forthcoming.

[37] Karlan, D., and List, J. (2007): Does Price Matter in Charitable Giving? Evidence from a Large-Scale Natural Field Experiment, American Economic Review, 97(5): 1774-1793.

[38] Kitzmueller, M. and Shimshack, J. (2012): Economic Perspectives on Corporate Social Responsibility, Journal of Economic Literature, 50(1), 51-84.

[39] Koppel, H. and Regner, T. (2013): Corporate Social Responsibility in the work place - Experimental evidence on CSR from a gift-exchange game, Experimental Economics, forthcoming.

[40] Linardi, S. and McConnell, M. A. (2011): No Excuses for Good Behavior: Volunteering and the Social Environment, Journal of Public Economics, 95(5-6), 445-454.

[41] Prendergast, C. (2007): The Motivation and Bias of Bureaucrats, American Economic Review, 97(1): 180-196.

[42] Servaes, H. and Tamayo, A. (2013): The Impact of Corporate Social Responsibility on Firm Value: The Role of Customer Awareness, Management Science, forthcoming.

[43] Shearer, B. S. (2004): Piece Rates, Fixed Wages and Incentives: Evidence From a Field Experiment, Review of Economic Studies, 71(2), 513-34.

[44] Slonim, R., C. Wang, E. Garbarino, Merrett, D. (2013): Opting-in: Participation bias in economic experiments, Journal of Economic Behavior and Organization, 90, 43-70.

[45] Stites, J. P., and Michael, J. H. (2011): Organizational Commitment in Manufacturing Employees: Relationships With Corporate Social Performance, Business \& Society, 50(1), 50-70.

[46] Tonin, M., and Vlassopoulos, M. (2010): Disentangling the Sources of Prosocially Motivated Effort: A Field Experiment, Journal of Public Economics, 94(11-12), 1086-1092.

[47] Tonin, M., and Vlassopoulos, M. (2013): Sharing One's Fortune? An Experimental Study on Earned Income and Giving, IZA DP No. 7294. 


\section{Appendix A - Tables}

Table 2: Demographics

\begin{tabular}{|c|c|c|c|c|c|c|c|}
\hline & & All & Group 1 & Group 2 & Group 3 & Group 4 & $\chi^{2}$ test \\
\hline \multirow{2}{*}{$\begin{array}{l}\text { Gender } \\
(\mathrm{n}=320)\end{array}$} & Male (\%) & 55.9 & 46.2 & 51.9 & 58.0 & 60.3 & \multirow[t]{2}{*}{0.328} \\
\hline & Female (\%) & 44.1 & 53.9 & 48.1 & 42.0 & 39.7 & \\
\hline \multirow{2}{*}{$\begin{array}{l}\text { Country of Birth } \\
(\mathrm{n}=305)\end{array}$} & $\mathrm{UK}(\%)$ & 66.6 & 61.7 & 68.1 & 68.0 & 66.7 & \multirow[t]{2}{*}{0.886} \\
\hline & Other $(\%)$ & 33.4 & 38.3 & 31.9 & 32.0 & 33.3 & \\
\hline \multirow{2}{*}{$\begin{array}{l}\text { Age } \\
(\mathrm{n}=307)\end{array}$} & Mean & 21.2 & 20.8 & 20.9 & 21.4 & 21.4 & \multirow[t]{2}{*}{$0.68^{*}$} \\
\hline & $\mathrm{SD}$ & 3.74 & 2.04 & 2.75 & 4.82 & 3.63 & \\
\hline \multirow{2}{*}{$\begin{array}{l}\text { Ethnicity } \\
(\mathrm{n}=307)\end{array}$} & White (\%) & 73.9 & 68.1 & 78.4 & 71.9 & 76.1 & \multirow[t]{2}{*}{0.602} \\
\hline & Other $(\%)$ & 26.1 & 31.9 & 21.6 & 28.1 & 23.9 & \\
\hline \multirow{4}{*}{$\begin{array}{l}\text { Year of Study } \\
(\mathrm{n}=320)\end{array}$} & First & 44.4 & 42.3 & 59.6 & 46.0 & 37.1 & \multirow[t]{4}{*}{0.015} \\
\hline & Second & 24.4 & 11.5 & 19.2 & 23.0 & 33.6 & \\
\hline & Third & 20.3 & 30.8 & 13.5 & 17.0 & 21.6 & \\
\hline & Fourth and higher & 10.9 & 15.4 & 7.7 & 14.0 & 7.8 & \\
\hline \multirow{2}{*}{$\begin{array}{l}\text { Working } \\
(\mathrm{n}=309)\end{array}$} & Yes $(\%)$ & 20.7 & 18.8 & 21.6 & 17.5 & 23.9 & \multirow[t]{2}{*}{0.698} \\
\hline & No $(\%)$ & 79.3 & 81.3 & 78.4 & 82.5 & 76.1 & \\
\hline \multirow{2}{*}{$\begin{array}{l}\text { Volunteered } \\
(\mathrm{n}=306)\end{array}$} & Yes $(\%)$ & 44.4 & 46.8 & 52.9 & 61.5 & 55.4 & \multirow[t]{2}{*}{0.399} \\
\hline & No $(\%)$ & 55.6 & 53.2 & 47.1 & 38.5 & 44.6 & \\
\hline \multirow{2}{*}{$\begin{array}{l}\text { Donated Money } \\
(\mathrm{n}=307)\end{array}$} & Yes $(\%)$ & 80.1 & 79.2 & 76.0 & 83.3 & 79.7 & \multirow[t]{2}{*}{0.753} \\
\hline & No $(\%)$ & 19.9 & 20.8 & 24.0 & 16.7 & 20.4 & \\
\hline
\end{tabular}

Notes: $\chi^{2}$ test column reports p-values for a Fischer $\chi^{2}$ test, except for "Age" where the p-value is for an F-test of a regression of age on group dummies. 


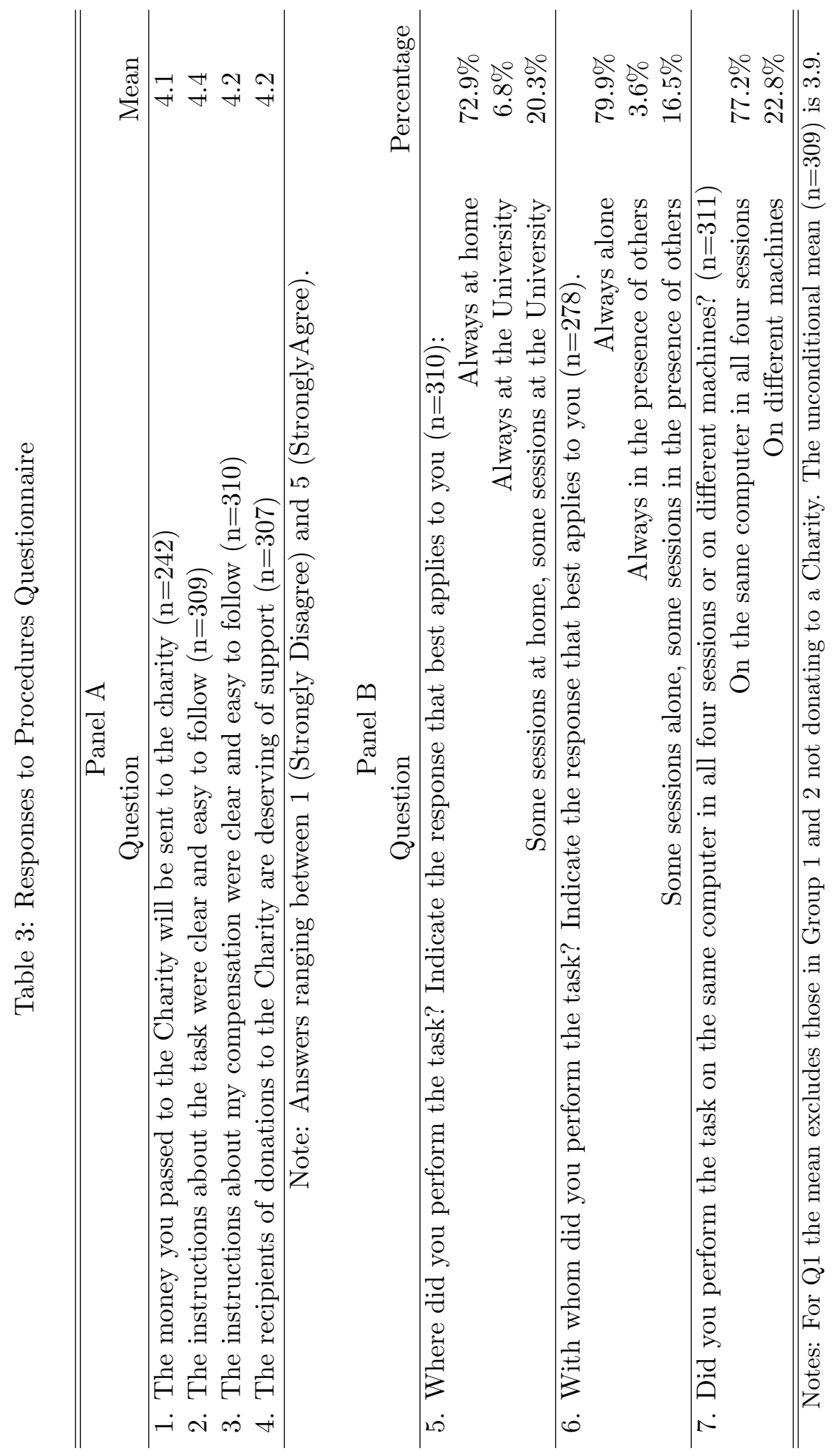




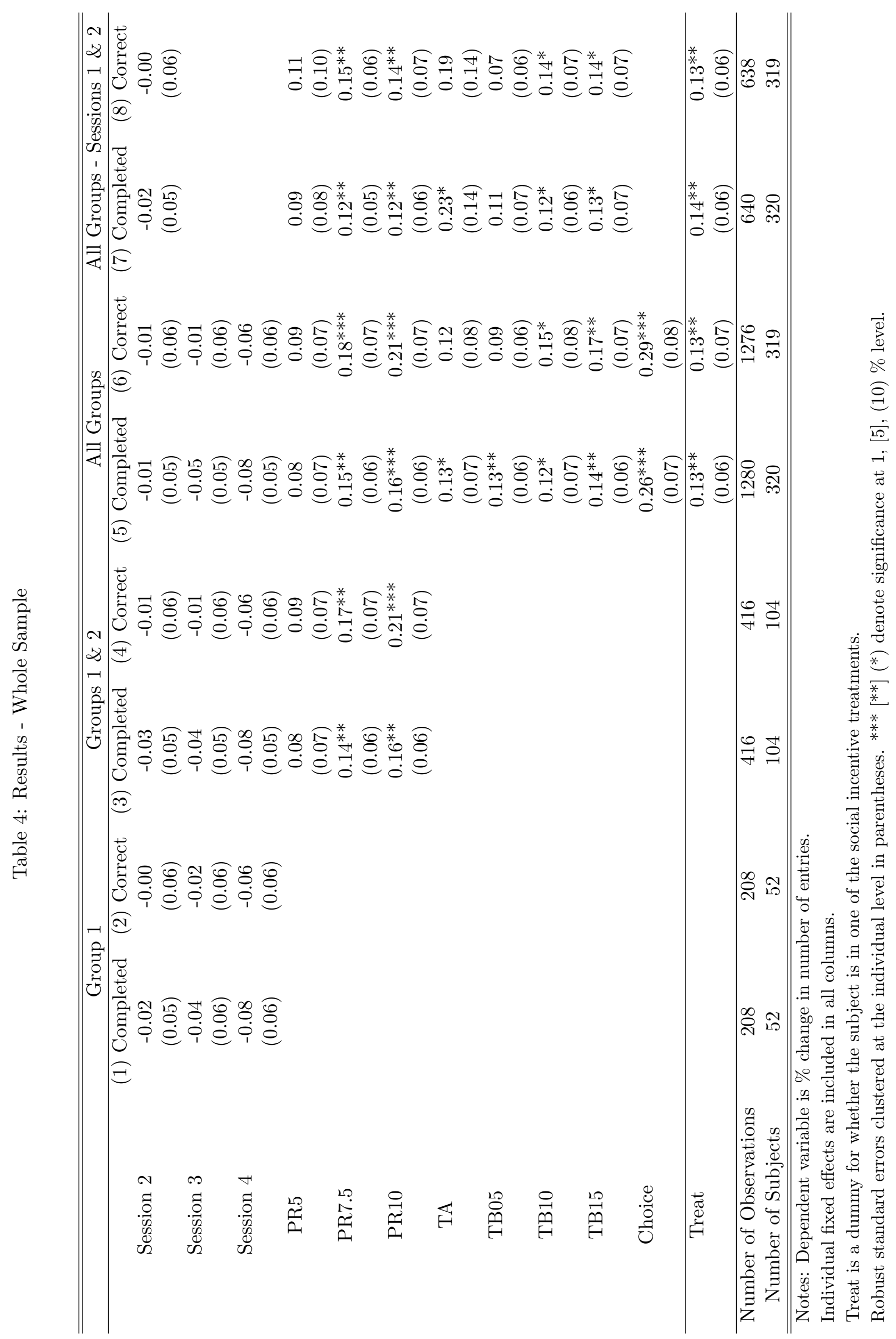


Table 5: Results - Productivity Split

\begin{tabular}{|c|c|c|c|c|}
\hline & \multicolumn{2}{|c|}{ Low Productivity } & \multicolumn{2}{|c|}{ High Productivity } \\
\hline \multirow{3}{*}{ PR5 } & (1) Completed & (2) Correct & (3) Completed & (4) Correct \\
\hline & $0.21^{*}$ & 0.19 & -0.04 & -0.00 \\
\hline & $(0.13)$ & $(0.15)$ & $(0.05)$ & $(0.06)$ \\
\hline \multirow{2}{*}{ PR7.5 } & $0.30 * * *$ & $0.31 * *$ & 0.02 & 0.07 \\
\hline & $(0.11)$ & $(0.14)$ & $(0.04)$ & $(0.04)$ \\
\hline \multirow[t]{2}{*}{ PR10 } & $0.32^{* *}$ & $0.37 * *$ & 0.02 & 0.06 \\
\hline & $(0.13)$ & $(0.15)$ & $(0.04)$ & $(0.04)$ \\
\hline \multirow[t]{2}{*}{ TA } & $0.29^{* *}$ & $0.28^{*}$ & -0.04 & -0.05 \\
\hline & $(0.13)$ & $(0.15)$ & $(0.05)$ & $(0.05)$ \\
\hline \multirow[t]{2}{*}{ TB05 } & $0.27^{* *}$ & $0.23^{*}$ & -0.01 & -0.05 \\
\hline & $(0.11)$ & $(0.12)$ & $(0.06)$ & $(0.05)$ \\
\hline \multirow[t]{2}{*}{ TB10 } & $0.28^{* *}$ & $0.33^{* *}$ & -0.04 & -0.04 \\
\hline & $(0.12)$ & $(0.16)$ & $(0.05)$ & $(0.05)$ \\
\hline \multirow[t]{2}{*}{ TB15 } & $0.27^{* *}$ & $0.30^{* *}$ & 0.02 & 0.03 \\
\hline & $(0.11)$ & $(0.14)$ & $(0.04)$ & $(0.04)$ \\
\hline \multirow[t]{2}{*}{ Choice } & $0.50^{* * *}$ & $0.58^{* * *}$ & 0.02 & 0.00 \\
\hline & $(0.13)$ & $(0.15)$ & $(0.04)$ & $(0.04)$ \\
\hline \multirow[t]{2}{*}{ Session 2} & -0.12 & -0.09 & $0.09^{* *}$ & $0.08^{* *}$ \\
\hline & $(0.10)$ & $(0.11)$ & $(0.03)$ & $(0.03)$ \\
\hline \multirow{2}{*}{ Session 3} & $-0.16^{*}$ & -0.09 & 0.05 & 0.05 \\
\hline & $(0.10)$ & $(0.11)$ & $(0.04)$ & $(0.04)$ \\
\hline \multirow[t]{2}{*}{ Session 4} & $-0.22^{* *}$ & $-0.19^{*}$ & 0.05 & $0.06^{*}$ \\
\hline & $(0.10)$ & $(0.11)$ & $(0.03)$ & $(0.03)$ \\
\hline \multirow[t]{2}{*}{ Constant } & -0.00 & 0.00 & 0.00 & 0.00 \\
\hline & $(0.03)$ & $(0.04)$ & $(0.01)$ & $(0.01)$ \\
\hline \multirow[t]{2}{*}{ Treat } & $0.28^{* *}$ & $0.29^{* *}$ & -0.01 & -0.03 \\
\hline & $(0.11)$ & $(0.13)$ & $(0.04)$ & $(0.04)$ \\
\hline Number of Observations & 632 & 628 & 632 & 628 \\
\hline Number of Subjects & 158 & 157 & 162 & 162 \\
\hline
\end{tabular}

Notes: Dependent variable is \% change in number of entries.

Individual fixed effects are included in all columns.

Treat is a dummy for whether the subject is in one of the social incentive treatments.

Robust standard errors clustered at the individual level in parentheses.

*** [**] $(*)$ denote significance at 1, [5], (10) \% level. 
Table 6: Results - Volunteering Split

\begin{tabular}{ccccc}
\hline \hline & \multicolumn{2}{c}{ Volunters } & \multicolumn{2}{c}{ Non-Volunteers } \\
\hline \multirow{2}{*}{ PR5 } & (1) Completed & $(2)$ Correct & $(3)$ Completed & (4) Correct \\
& 0.01 & -0.01 & 0.07 & 0.10 \\
PR7.5 & $(0.10)$ & $(0.11)$ & $(0.08)$ & $(0.10)$ \\
& 0.11 & $0.15^{*}$ & 0.10 & 0.12 \\
PR10 & $(0.08)$ & $(0.09)$ & $(0.08)$ & $(0.10)$ \\
& 0.09 & 0.12 & $0.16^{*}$ & $0.20^{* *}$ \\
TA & $(0.09)$ & $(0.10)$ & $(0.08)$ & $(0.10)$ \\
& 0.12 & 0.13 & 0.08 & 0.04 \\
TB05 & $(0.09)$ & $(0.09)$ & $(0.10)$ & $(0.12)$ \\
& $0.20^{* *}$ & 0.11 & 0.01 & 0.01 \\
TB10 & $(0.09)$ & $(0.09)$ & $(0.08)$ & $(0.09)$ \\
& 0.14 & 0.15 & 0.05 & 0.08 \\
TB15 & $(0.09)$ & $(0.10)$ & $(0.09)$ & $(0.13)$ \\
& $0.19^{* *}$ & $0.25^{* *}$ & 0.05 & 0.03 \\
Choice & $(0.08)$ & $(0.11)$ & $(0.08)$ & $(0.09)$ \\
& $0.20^{* *}$ & $0.21^{* *}$ & $0.25^{* *}$ & $0.30^{* *}$ \\
Session 2 & $(0.08)$ & $(0.11)$ & $(0.10)$ & $(0.12)$ \\
& -0.04 & -0.04 & 0.08 & 0.11 \\
Session 3 & $(0.07)$ & $(0.08)$ & $(0.06)$ & $(0.07)$ \\
& -0.07 & -0.02 & 0.04 & 0.08 \\
Session 4 & $(0.07)$ & $(0.08)$ & $(0.07)$ & $(0.08)$ \\
& -0.06 & -0.03 & -0.01 & -0.00 \\
Constant & $(0.08)$ & $(0.08)$ & $(0.07)$ & $(0.07)$ \\
& -0.00 & 0.00 & 0.00 & 0.00 \\
Treat & $(0.02)$ & $(0.03)$ & $(0.03)$ & $(0.03)$ \\
\hline \hline Number of Subjects & $0.17^{* *}$ & $0.16^{* *}$ & 0.05 & 0.04 \\
& $(0.08)$ & $(0.09)$ & $(0.08)$ & $(0.09)$ \\
\hline \hline
\end{tabular}

Notes: Dependent variable is \% change in number of entries.

Individual fixed effects are included in all columns.

Treat is a dummy for whether the subject is in one of the social incentive treatments.

Robust standard errors clustered at the individual level in parentheses.

*** [**] $(*)$ denote significance at 1, [5], (10) \% level. 


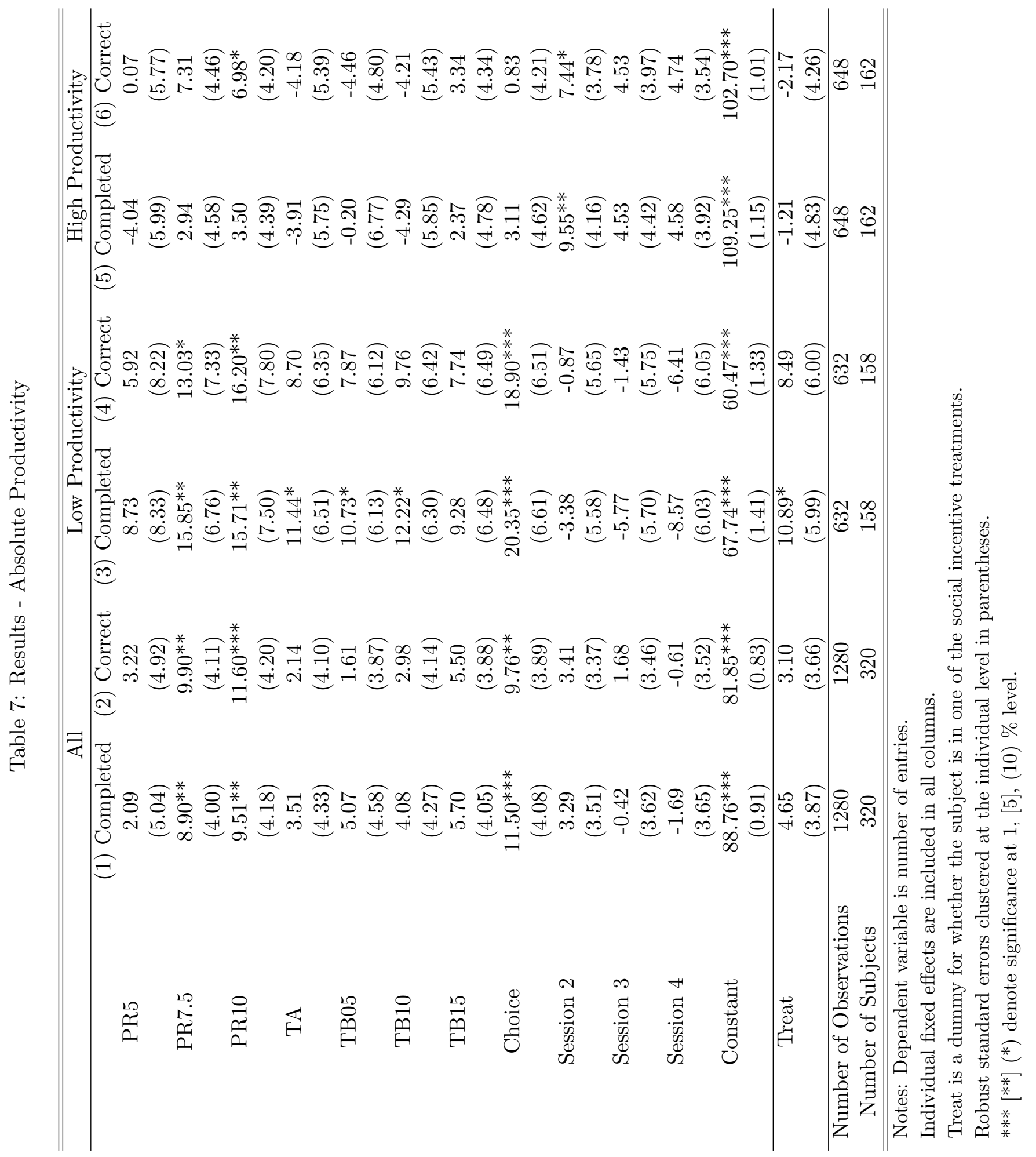


Table 8: Results - Accuracy

\begin{tabular}{|c|c|c|c|}
\hline & $\overline{\text { All }}$ & $\begin{array}{c}\text { Low } \\
\text { Productivity }\end{array}$ & $\begin{array}{c}\text { High } \\
\text { Productivity }\end{array}$ \\
\hline PR5 & $\begin{array}{c}0.01 \\
(0.02)\end{array}$ & $\begin{array}{l}-0.02 \\
(0.03)\end{array}$ & $\begin{array}{l}0.02^{*} \\
(0.01)\end{array}$ \\
\hline PR7.5 & $\begin{array}{c}0.02 \\
(0.02)\end{array}$ & $\begin{array}{c}0.00 \\
(0.05)\end{array}$ & $\begin{array}{l}0.04^{* *} \\
(0.01)\end{array}$ \\
\hline PR10 & $\begin{array}{c}0.02 \\
(0.02)\end{array}$ & $\begin{array}{c}0.02 \\
(0.03)\end{array}$ & $\begin{array}{c}0.03^{* *} \\
(0.01)\end{array}$ \\
\hline TA & $\begin{array}{c}0.00 \\
(0.01)\end{array}$ & $\begin{array}{c}0.00 \\
(0.02)\end{array}$ & $\begin{array}{l}-0.00 \\
(0.01)\end{array}$ \\
\hline TB05 & $\begin{array}{l}-0.02 \\
(0.01)\end{array}$ & $\begin{array}{l}-0.02 \\
(0.02)\end{array}$ & $\begin{array}{l}-0.01 \\
(0.02)\end{array}$ \\
\hline TB10 & $\begin{array}{l}-0.01 \\
(0.01)\end{array}$ & $\begin{array}{l}-0.01 \\
(0.03)\end{array}$ & $\begin{array}{l}-0.00 \\
(0.01)\end{array}$ \\
\hline TB15 & $\begin{array}{c}0.00 \\
(0.01)\end{array}$ & $\begin{array}{l}-0.01 \\
(0.02)\end{array}$ & $\begin{array}{c}0.01 \\
(0.01)\end{array}$ \\
\hline Choice & $\begin{array}{l}-0.00 \\
(0.01)\end{array}$ & $\begin{array}{c}0.00 \\
(0.02)\end{array}$ & $\begin{array}{l}-0.01 \\
(0.01)\end{array}$ \\
\hline Session 2 & $\begin{array}{c}0.01 \\
(0.01)\end{array}$ & $\begin{array}{c}0.02 \\
(0.02)\end{array}$ & $\begin{array}{l}-0.00 \\
(0.01)\end{array}$ \\
\hline Session 3 & $\begin{array}{l}0.02^{* *} \\
(0.01)\end{array}$ & $\begin{array}{l}0.04^{* *} \\
(0.02)\end{array}$ & $\begin{array}{c}0.00 \\
(0.01)\end{array}$ \\
\hline Session 4 & $\begin{array}{c}0.01 \\
(0.01)\end{array}$ & $\begin{array}{c}0.02 \\
(0.02)\end{array}$ & $\begin{array}{c}0.01 \\
(0.01)\end{array}$ \\
\hline Constant & $\begin{array}{c}0.92^{* * *} \\
(0.00) \\
\end{array}$ & $\begin{array}{c}0.89^{* * *} \\
(0.01)\end{array}$ & $\begin{array}{c}0.94^{* * * *} \\
(0.00)\end{array}$ \\
\hline Treat & $\begin{array}{l}-0.00 \\
(0.01)\end{array}$ & $\begin{array}{l}-0.01 \\
(0.02)\end{array}$ & $\begin{array}{l}-0.00 \\
(0.01)\end{array}$ \\
\hline Number of Observations & 1273 & 625 & 648 \\
\hline Number of Subjects & 320 & 158 & 162 \\
\hline
\end{tabular}

Notes: Dependent variable the number of correct entries divided by the number of complete entries. Individual fixed effects are included in all columns.

Treat is a dummy for whether the subject is in one of the social incentive treatments.

Robust standard errors clustered at the individual level in parentheses.

*** [**] $(*)$ denote significance at $1,[5],(10) \%$ level. 
Time Remaining: 0 minute Bonus per record: $5 p$ Records Entered: 0

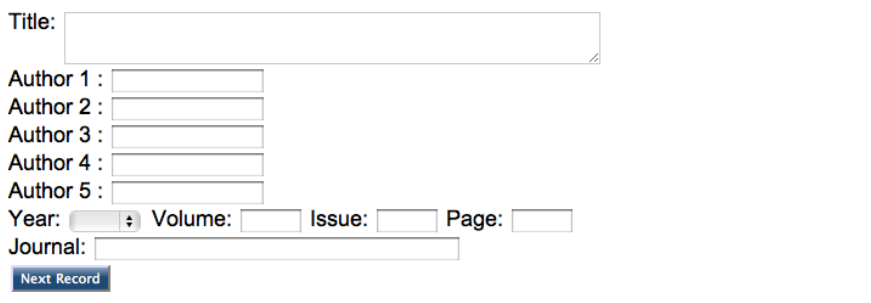

An Untapped Resource Using YouTube in Nursing Education

Agazio, Janice and Buckley, Kathleen M. (2009) An Untapped Resource Using YouTube in Nursing Education, NURSE EDUCATOR, Volume 34, Issue 1, Page 23-28

\section{Abstract}

Minimal information is available in the literature addressing video sharing in nursing education. Using Multiple examples, the authors discuss the use of YouTube, a popular video-sharing and social networking site. YouTube is used to illustrate theoretical content, involve students, and inspire innovative teaching methods. Faculty can use this content, involve students, and inspire innovative teaching methods. Faculty can use this
technology to stimulate Student discussions, share information, and create a learning

Figure 5: Screenshot of Task Page 